\title{
Intratumoral hemorrhage and deadly upward transtentorial herniation after endoscopic third ventriculostomy in the management of posterior fossa tumor-related hydrocephalus - Case report and literature review
}

\author{
Johnathan de Sousa Parreira ${ }^{1}$, Adelmo Ferreira ${ }^{2}$, Adriano Torres Antonucci ${ }^{3}$, Natally Marques Santiago ${ }^{3}$, \\ Roberto Parente Neto ${ }^{3}$, Bruno de Azevedo Oliveira1 , Luiz Henrique Garcia Lopes ${ }^{1}$, Pedro Garcia Lopes ${ }^{1}$ \\ University Hospital of Northern Paraná, Londrina, PR, Brazil and Neurosurgical and Neurological Institute of Western Amazon, \\ INAO, Porto Velho, RO, Brazil.
}

\section{ABSTRACT}

The management of hydrocephalus associated with posterior fossa tumors in children has always been controversial. Studies show that $71 \%-90 \%$ of children with posterior fossa tumors already presented hydrocephalus on admission. Of these cases, $10 \%-62 \%$ will have persistent hydrocephalus after surgical treatment of the tumor. The shunt, although it is an important alternative for preoperative treatment in these cases is not without complications. Among the numerous complications identified by the literature, we highlight the most rare, intratumoral hemorrhage, upward transtentorial herniation and dissemination of neoplastic cells by the peritoneum. Medulloblastoma is considered the most common malignant pediatric tumor, comprising $15 \%-20 \%$ of all intracranial tumors in childhood. In addition, $5 \%-6 \%$ of primary or recurrent medulloblastomas may be associated with spontaneous bleeding and rapid deterioration. The bleeding presents with tumor swelling, extending to the ventricular system through the tumor capsule, increased intracranial pressure and upward transtentorial herniation. Tumoral hemorrhage associated with ventricular drainage for treatment of hydrocephalus in patients with medulloblastoma represents an extremely rare phenomenon. The endoscopy third-ventriculostomy (ETV) is known to be very useful in the treatment of intracranial hypertension preoperatively and prevent persistent postoperative hydrocephalus in cases associated with posterior fossa tumors, with efficacy superior to traditional ventricular shunts. We describe a case of intratumoral hemorrhage and upward transtentorial herniation associated with endoscopic third-ventriculostomy (ETV).

\section{KEYWORDS}

Ventriculostomy, third ventricle, hemorrhage.

\section{RESUMO}

Hemorragia tumoral e herniação transtentorial ascendente fatal após terceiro-ventriculostomia endoscópica para tratamento de hidrocefalia secundária a tumor de fossa posterior - Relato de caso e revisão de literatura

O manejo da hidrocefalia associada a tumores de fossa posterior em crianças sempre foi controverso. Trabalhos mostram que $71 \%-90 \%$ das crianças com tumores de fossa posterior já se apresentam hidrocefálicos na admissão. Desses casos, 10\%-62\% terão hidrocefalia persistente após o tratamento cirúrgico do tumor. A derivação ventricular, embora consista em importante alternativa de tratamento pré-operatório nesses casos, não está isenta de complicações. Dentre as inúmeras complicações apontadas pela literatura atual, particularmente nos casos de meduloblastoma que necessitaram de derivação ventricular por hidrocefalia, destacamos as mais raras: hemorragia tumoral, herniação transtentorial ascendente e disseminação de células neoplásicas pelo peritônio. $O$ meduloblastoma é considerado o tumor pediátrico maligno mais comum, compreendendo $15 \%-20 \%$ de todas as neoplasias intracranianas na infância. Além disso, 5\%-6\% dos meduloblastomas primários ou recorrentes podem estar associados à hemorragia espontânea e rápida deterioração. A hemorragia cursa com aumento de volume do tumor, extravasamento para o sistema ventricular através da cápsula tumoral, aumento da pressão intracraniana e herniação transtentorial ascendente. Hemorragia tumoral associada à drenagem ventricular, para tratamento de hidrocefalia em portadores de meduloblastoma, representa um fenômeno extremamente raro. A terceiroventriculostomia endoscópica (TVE) é reconhecida por ser bastante útil no tratamento da hipertensão intracraniana no pré-operatório e por prevenir a hidrocefalia persistente pós-operatória nos casos associados a tumores de fossa posterior, com eficácia superior às derivações ventriculares tradicionais. Descrevemos um caso de hemorragia tumoral e herniação transtentorial ascendente associados a terceiro-ventriculostomia endoscópica (TVE).

\section{PALAVRAS-CHAVE}

Ventriculostomia, terceiro ventrículo, hemorragia.

1 Neurosurgeon of the Neurosurgical and Neurological Institute of Western Amazon, INAO, Porto Velho, RO, Brazil.

2 Neurosurgeon and Instructor of the University Hospital of Northern Paraná, Londrina, PR, Brazil.

3 Neurosurgery-resident of the University Hospital of Northern Paraná, Londrina, Paraná, Brazil. 


\section{Introduction}

Intratumoral hemorrhage is observed in various brain tumors, mainly medulloblastoma, glioblastoma, pituitary adenoma and oligodendroglioma. ${ }^{1}$ Medulloblastoma is the most common malignant tumor, accounting for $15 \%-20 \%$ of all intracranial tumors in childhood and 5\%-6\% of medulloblastomas may have spontaneous intratumoral hemorrhage with rapid deterioration. ${ }^{2}$ Upward transtentorial herniation associated with posterior fossa tumors represent the rarest complication. Anatomically implies rostral displacement of the upper vermis through the tentorial notch. The early radiological signs of herniation are: disappearance of the cistern and compression of the quadrigeminal plate, resulting in compression of the Sylvius aqueduct and acute hydrocephalus. The management of hydrocephalus associated with posterior fossa tumors in childhood has always been problematic. Although most of these patients do not require permanent cerebrospinal fluid (CSF) shunt valve, those undergoing this treatment seem to suffer with higher postoperative complications. ${ }^{3}$ In the past, they used to proceed with the shunt routinely preoperatively however technological advances have enabled early diagnosis in anticipation of definitive surgical intervention. ${ }^{4}$ Currently, one third of patients will eventually require CSF shunt, ${ }^{3}$ decreasing dramatically the incidence of complications associated with the procedure like infections, intratumoral hemorrhage and the rarest of them, upward transtentorial herniation. Factors associated with the need for shunt include: age less than 10 years, tumors in the midline, partial resection of the tumor, shunt-related infections and persistent pseudomeningocele. ${ }^{5}$ We report a rare case of intratumoral hemorrhage and upward transtentorial herniation after endoscopic third ventriculostomy (ETV) for the treatment of hydrocephalus secondary to posterior fossa medulloblastoma.

\section{Case report}

Female, 9 years old, presenting unmotivated vomiting for a month and progressive headache that becoming refractory to opioids. On physical examination, we observed left hemiparesis, sixth nerve palsy, dysmetria and dysdiadocokinesia. Computed tomography (CT) without contrast, showed expansive formation inside the fourth ventricle, causing dilation of the supratentorial ventricular system. Magnetic resonance imaging (MRI) of the brain confirmed bulky lesion within the fourth ventricle, apparently infiltrating the lower aspect of the vermis, measuring $6.1 \times 3.3 \mathrm{x}$ $3.7 \mathrm{~cm}$, showing component insinuating itself through mesencephalic aqueduct, showing heterogeneous appearance, with cystic areas inside, and intense enhancement after contrast agent with supratentorial ventricular dilatation associated with CSF transudation (Figures 1 and 2).

Based on the clinical outcome and imaging tests, we programmed primarily ETV for treatment of obstructive hydrocephalus and microsurgical resection oh the tumor in a second intervention. Endoscopic surgery was

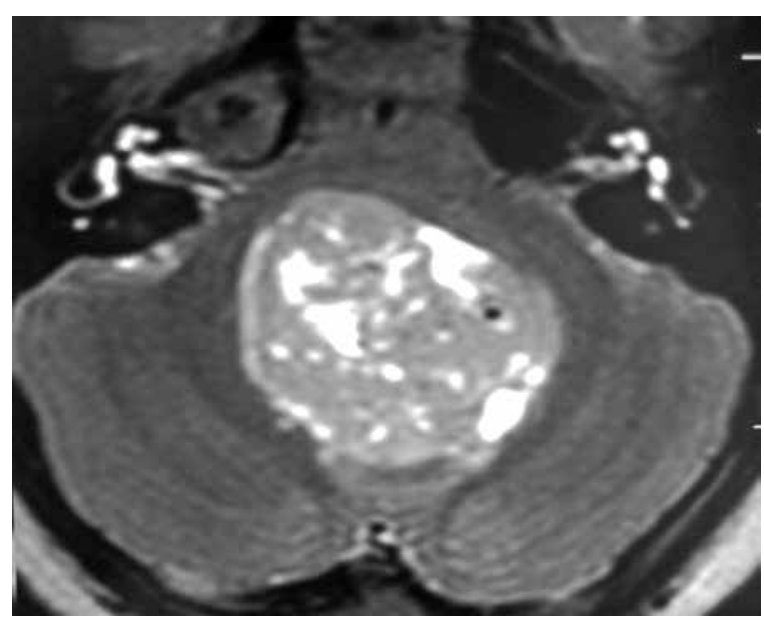

Figure 1 - Axial MRI showing solid tumor occupying the entire fourth ventricle.

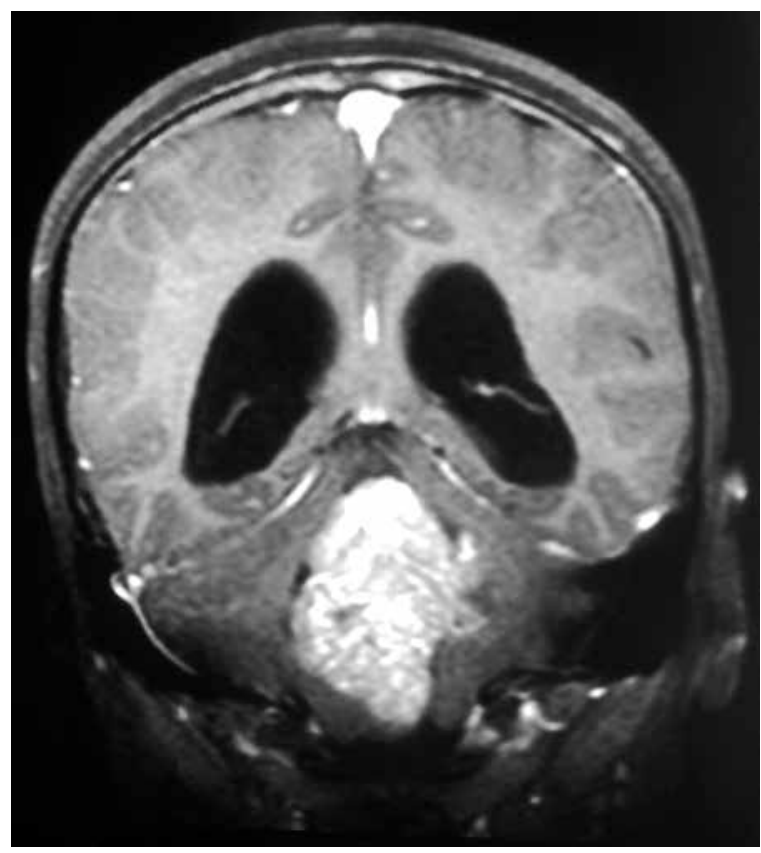

Figure 2 - Coronal MRI showing dilatation of the supratentorial ventricular system caused by the tumor in the posterior fossa. 
performed by burr hole in front of the coronal suture on the mid-pupillary line. Fenestration is performed at the tuber cinereum at the midway between the infundibular recess and the intermamillary point using a Fogarty catheter. The patient was awakened in the operating room and was referred for observation in the intensive care unit (ICU), where she was admitted with mild drowsiness. Sixty minutes after the ETV, the patient developed apnea, bradycardia followed by cardiac arrest. Was promptly resuscitated, presenting in coma since then, assisted ventilation, with fixed-medium pupils and absence of other brainstem reflexes, with need for vasoactive drugs to maintain hemodynamic patterns. The patient was referred for urgent CT scan, which showed extensive bleeding inside the third ventricle, with signs of upward transtentorial herniation. Facing up the severe clinical picture, we adopted conservative treatment and following the protocol of brain death. The patient died two days after the ETV. The patient was referred for performing autopsy, which showed extensive subarachnoid and intraventricular hemorrhage with upward herniation of the brainstem and cerebellum by the tentorial notch. Histological study of the tumor confirms medulloblastoma with numerous intratumoral hemorrhagic foci.

\section{Discussion}

The ETV has been accepted as the procedure of choice for treatment of non-communicating hydrocephalus. This procedure is considered fast and efficient. It is recognized as having effect in relieving intracranial hypertension preoperatively and prevent persistent postoperative hydrocephalus in cases associated with posterior fossa tumors, with efficacy superior to traditional ventricular shunts, reducing the incidence of hydrocephalus persistent postoperative from $27 \%$ to $6 \%$, with a success rate of $70 \%-80 \%$ in the resolution of obstructive hydrocephalus and complication rate of 6\%-9\%. However, studies seeking the lifting of the complications of such treatment modality are still scarce. In literature, work focused on complications of procedures neuroendoscopic, published by Teo et al..$^{5}$ evaluated 173 cases, of which 55 were ETVs. In these patients, the authors found a clinically significant complication rate of $9 \%$. Most data of severe complications of ETV was published as case reports. Lethal complications or permanent deficits have rarely been reported..$^{5-8}$ However, it is believed that the rate of complications of the TVE is overestimated. ${ }^{9,10}$ A fatal complication most commonly reported in the literature is bleeding due to injury of basilar artery or perforating arteries. ${ }^{5}$ Transient complications are also cited, namely: hemiparesis, meningitis, ventriculitis, subdural hematoma, seizures, memory impairment, cerebrospinal fluid leak, diabetes insipidus, amenorrhea, sixth nerve palsy. ${ }^{5}$ Schroeder et al. ${ }^{11}$ published a study on complications occurred in 193 EVTs performed in 188 patients from 1993 to 2001 at a single institution, with an average age of 39 years, with 2 deaths ( $1 \%$ mortality) caused by hemorrhage secondary to artery basilar injury and sepsis secondary to meningitis. Other complications were reported: severe venous hemorrhage preventing the procedure (1 case); significant venous bleeding controlled endoscopically through copious irrigation (2 cases), subdural hematoma ( 3 cases); thalamic injury (1 case); cortical hemorrhage in place puncture (1 case); permanent deficit described as mental confusion, oculomotor palsy and diabetes insipidus (3 cases) permanent morbidity rate of $1.6 \%$; deficit described as transient meningitis (4 cases), cerebrospinal fluid leak (3 cases), herniation syndrome ( 2 cases), confusion ( 2 cases), decreased level of consciousness (1 case), oculomotor nerve palsy ( 2 cases) and loss of feeling thirsty (one case) - transient morbidity 7, 8\%.

The association of posterior fossa tumors with hydrocephalus represents a potentially lethal condition that requires urgent surgical treatment. ${ }^{12,13}$ The best option for the surgical management of hydrocephalus in these cases is still controversial. Neuroimaging technological improvements allow for the early diagnosis of neoplasms and other conditions related to it such as, for example, hydrocephalus. Allying themselves with this knowledge about possible complications of ventricular shunting (infection, malfunction of the system, tumor hemorrhage and upward transtentorial herniation) made possible the initial adoption of conservative measures, questioning the need to perform routine shunt. ${ }^{14-16}$ The result was the choice of alternative therapies, such as corticosteroids and early surgery to remove the tumor, with the completion of external ventricular drainage only when necessary during surgery, keeping it postoperatively for 24 to 48 hours only. ${ }^{17-19}$ It is noteworthy that, although theoretically attractive, external ventricular drainage preoperative is not without risks, with fatal complications already well described in the literature. ${ }^{20}$ Consequently, several authors ${ }^{3,21}$ have attempted to identify patients with increased risk of requiring placement of a shunt postoperatively. Younger age at diagnosis proved to be important for most authors (aged below 10 years), as well as the location of the tumor in the midline, the incomplete removal of the same, the use of grafts of dura mater during the closure. Tumor size and the need to use external ventricular drainage pre-and intraoperative not appear to have direct influence. 
Intracranial tumors are recognized as rare causes of intracranial hemorrhage, accounting for $6 \%-10 \%$ of them..$^{22}$ In malignant tumors, such as medulloblastoma, the pathophysiological mechanism of tumor bleeding would be described as spontaneous secondary to immaturity, fragility and structural abnormalities of the vessels of the tumor as well as necrotic changes, leading to rupture by stretching the vessel. ${ }^{2}$ In a series of 144 patients with medulloblastoma, published by Park et al. ${ }^{23} 8$ of them showed spontaneous intratumoral hemorrhage, 1 patient died suddenly while 4 had sudden neurologic deterioration. In 3 patients, we detected a recurrent medulloblastoma. Spontaneous intratumoral hemorrhage in medulloblastoma, secondary to ventricular shunting procedures are particularly rare. ${ }^{24,25}$

Elgamal et al. ${ }^{20}$ have published case in which there acute internal hemorrhage, followed by upward transtentorial herniation in case of medulloblastoma, upon insertion of an external ventricular drainage. The first case would have been published by Vaquero et al. ${ }^{24}$ together with a fatal bleeding after external ventricular drainage in a case of cerebellar astrocytoma. Santi et al. ${ }^{26}$ published a case report in which a male patient, 14 years of age, was admitted to the emergency room with sudden severe headache with progressive worsening for 1 day. Computed tomography without contrast, revealed that it was a hemorrhagic tumor in the posterior fossa. The patient was immediately intubated and underwent external ventricular drainage. Magnetic resonance imaging (MRI) revealed a large tumor with hemorrhagic upward transtentorial herniation. The patient died in two days despite aggressive therapeutic measures. Necropsy and lesion analysis were performed and showed treating medulloblastoma.

Regarding the details of the technique used in the case reported here, we have not seen any complications that may have influenced the outcome of the case. We used routinely Fogarty catheter for dilation of the stoma in tuber cinerium as described in the literature. ${ }^{27}$ However, in our patient, the tumor in forth ventricle or ETV maybe have created a large pressure gradient and precipitated upward herniation. If this reasoning is true, perhaps the use of refinements to the measurement of intracranial pressure in third ventricle or making of a smaller stoma can help.

\section{Conclusion}

The literature review showed that a minority of primary or recurrent medulloblastomas may be associated with spontaneous bleeding and rapid deterioration. The hemorrhage progresses with increase of tumor, extravasation into the ventricular system through the capsule, increased intracranial pressure and upward transtentorial herniation. Tumor hemorrhage associated with ventricular drainage for the treatment of hydrocephalus in patients with medulloblastoma represents an extremely rare phenomenon. The management of hydrocephalus associated with posterior fossa tumors in children has always been controversial. The shunt is an important alternative for preoperative treatment in these cases but is not without complications. Among the many complications reported in the literature in cases of medulloblastoma who required shunt for hydrocephalus, highlight the rarest: tumor haemorrhage, ascending transtentorial herniation and spread of cancer cells by peritoneum. ETV is very useful in reducing intracranial hypertension preoperatively and prevent the persistent postoperative hydrocephalus in cases associated with posterior fossa tumors, with efficacy superior to traditional ventricular shunts, reducing the incidence of hydrocephalus persistent postoperative from $27 \%$ to $6 \%$, with a success rate of $70-80 \%$ in the resolution of obstructive hydrocephalus, however can also cause serious complications such as reported here.

\section{Competing interests}

The authors declare no conflict of interest.

\section{References}

1. Byard RW, Bourne AJ, Hanieh A. Sudden and unexpected death due to hemorrhage from occult central nervous system lesions. A pediatric autopsy study. Pediatr Neurosurg. 1991-1992;17(2):88-94.

2. Zimmerman RA, Bilaniuk LT. Computed tomography of acute intratumoral hemorrhage. Radiology. 1980;135(2):355-9.

3. Lee M, Wisoff JH, Abbott R, Freed D, Epstein FJ. Management of hydrocephalus in children with medulloblastoma: prognostic factors for shunting. Pediatr Neurosurg. 1994;20(4):240-7.

4. Albright L, Reigel DH. Management of hydrocephalus secondary to posterior fossa tumors. J Neurosurg. 1977;46(1):52-5.

5. Teo C, Rahman S, Boop FA, Cherny B. Complications of endoscopic neurosurgery. Childs Nerv Syst. 1996;12(5):24853.

6. Jones RF, Kwok BC, Stening WA, Vonau M. The current status of endoscopic third ventriculostomy in the management of non-communicating hydrocephalus. Minim Invasive Neurosurg. 1994;37(1):28-36.

7. McLaughlin MR, Wahlig JB, Kaufmann AM, Albright AL. Traumatic basilar aneurysm after endoscopic 
third ventriculostomy: case report. Neurosurgery. 1997;41(6):1400-3.

8. Schroeder HW, Warzok RW, Assaf JA, Gaab MR. Fatal subarachnoid hemorrhage after endoscopic third ventriculostomy. Case report. J Neurosurg. 1999;90(1):1535.

9. Abtin K, Thompson BG, Walker ML. Basilar artery perforation as a complication of endoscopic third ventriculostomy. Pediatr Neurosurg. 1998;28(1):35-41.

10. Buxton N, Punt J. Cerebral infarction after neuroendoscopic third ventriculostomy: case report. Neurosurgery. 2000;46(4):999-1001.

11. Schroeder HW, Niendorf WR, Gaab MR. Complications of endoscopic third ventriculostomy. J Neurosurg. 2002;96(6):1032-40.

12. Raimondi AJ, Tomita T. Hydrocephalus and infratentorial tumors. Incidence, clinical picture, and treatment. J Neurosurg. 1981;55(2):174-82.

13. Stein BM, Tenner MS, Fraser RA. Hydrocephalus following removal of cerebellar astrocytomas in children. J Neurosurg. 1972;36(6):763-8.

14. Epstein F, Murali R. Pediatric posterior fossa tumors: hazards of the "preoperative" shunt. Neurosurgery. 1978;3(3):348-50

15. Forrest DM, Cooper DGW: Complications of ventriculo-atrial shunts. A review of 455 cases. J Neurosurg. 1968;29:50612.

16. McLaurin RL. Disadvantages of the preoperative shunt in posterior fossa tumors. Clin Neurosurg. 1983;30:286-92.

17. Muszynski CA, Laurent JP, Cheek WR. Effects of ventricular drainage and dural closure on cerebrospinal fluid leaks after posterior fossa tumor surgery. Pediatr Neurosurg. 1994;21(4):227-31.

18. Rappaport ZH, Shalit MN. Perioperative external ventricular drainage in obstructive hydrocephalus secondary to infratentorial brain tumours. Acta Neurochir (Wien). 1989;96(3-4):118-21.

19. Shalit MN, Ben Ari Y, Eynan N. The management of obstructive hydrocephalus by the use of external continuous ventricular drainage. Acta Neurochir (Wien). 1979;47(3-4):161-72.
20. Elgamal EA, Richards PG, Patel UJ. Fatal haemorrhage in medulloblastoma following ventricular drainage. Case report and review of the literature. Pediatr Neurosurg. 2006;42(1):45-8.

21. Culley DJ, Berger MS, Shaw D, Geyer R. An analysis of factors determining the need for ventriculoperitoneal shunts after posterior fossa tumor surgery in children. Neurosurgery. 1994;34(3):402-7.

22. Yokota A, Kajiwara H, Matsuoka S, Kohchi M, Matsukado Y. Subarachnoid hemorrhage from brain tumors in childhood. Childs Nerv Syst. 1987;3(2):65-9.

23. Park TS, Hoffman HJ, Hendrick EB, Humphreys RP, Becker LE. Medulloblastoma: clinical presentation and management. Experience at the hospital for sick children, toronto, 1950-1980. J Neurosurg. 1983;58(4):543-52.

24. Vaquero J, Cabezudo JM, de Sola RG, Nombela L. Intratumoral hemorrhage in posterior fossa tumors after ventricular drainage. Report of two cases. J Neurosurg. 1981;54(3):406-8.

25. Wakai S, Yamakawa K, Manaka S, Takakura K. Spontaneous intracranial hemorrhage caused by brain tumor: its incidence and clinical significance. Neurosurgery. 1982;10(4):437-44.

26. Santi M, Kadom N, Vezina G, Rushing EJ. Undiagnosed medulloblastoma presenting as fatal hemorrhage in a 14-year-old boy: case report and review of the literature. Childs Nerv Syst. 2007;23(7):799-805.

27. Pople IK, Edwards RJ, Aquilina K. Endoscopic methods of hydrocephalus treatment. Neurosurg Clin N Am. 2001;12(4):719-35.

\section{Correspondence address}

Johnathan de Sousa Parreira Instituto de Neurocirurgia e Neurologia da Amazônia Ocidental (INAO)

Rua Rafael Vaz e Silva, 1663,

Nossa Senhora das Graças

76804-140 - Porto Velho, Rondônia, Brasil

Phone: (+55 69) 9947-4048

E-mail: jsparreira@yahoo.com.br 